\title{
ITGA5 is a prognostic biomarker and correlated with immune infiltration in gastrointestinal tumors
}

\author{
Hai Zhu ${ }^{1 \dagger}$, Gang Wang ${ }^{2 \dagger}$, Haixing Zhu ${ }^{3}$ and Aman $\mathrm{Xu}^{1,2^{*}}$
}

\begin{abstract}
Background: Integrin Subunit Alpha 5 (ITGA5), belongs to the integrin alpha chain family, is vital for promoting cancer cell invasion, metastasis. However, the correlation between ITGA5 expression and immune infiltration in gastrointestinal tumors remain unclear.

Methods: The expression level of ITGA5 was detected by Oncomine and Tumor Immune Estimation Resource (TIMER). The association between ITGA5 and prognosis of patients was identified by Kaplan-Meier plotter, Gene Expression Profiling Interactive Analysis 2 (GEPIA2) and PrognoScan. We evaluated the correlation between ITGA5 expression and immune infiltrating level via TIMER. Besides, TIMER, immunohistochemistry (IHC) staining and western blot were used to explore correlations between ITGA5 expression and markers of immune infiltrates cells. Furthermore, we constructed protein-protein interaction (PPI) network and performed functional enrichment by GeneMANIA and Metascape.
\end{abstract}

Results: ITGA5 was generally overexpressed and correlated with worse prognosis in multiple types of gastrointestinal tumors. In addition, ITGA5 expression level was significantly associated with tumor purity and immune infiltration levels of different immune cells in gastrointestinal tumors. Interestingly, immune markers for monocytes, tumor - associated macrophages (TAMs), macrophages 2 (M2) cells and T-helper 2 (Th2) cells were found to be significantly and positively correlated with ITGA5 expression levels in colon and gastric cancer. Results from IHC staining and western blot further proved that markers of Th2 and M2 cell were significantly increased in gastric cancer patients with high ITGA5 expression levels. Lastly, interaction network and function enrichment analysis revealed ITGA5 was mainly involved in "integrin mediated signaling pathway", "leukocyte migration", "cellsubstrate adhesion".

Conclutions: Our study demonstrated that ITGA5 may act as an essential regulator of tumor immune cell infiltration and a valuable prognostic biomarker in gastrointestinal tumors. Additional work is needed to fully elucidate the underlying mechanisms behind these observations.

Keywords: ITGA5, Gastrointestinal tumor, Immune, Prognosis, Tumor-associated macrophages

\footnotetext{
* Correspondence: amanxuahmu@126.com

${ }^{\dagger} \mathrm{Hai}$ Zhu and Gang Wang contributed equally to this work.

'Department of General Surgery, The First Affiliated Hospital of Anhui

Medical University, Hefei 230001, People's Republic of China

${ }^{2}$ Department of General Surgery, The Fourth Affiliated Hospital of Anhui

Medical University, Hefei 230001, People's Republic of China

Full list of author information is available at the end of the article
} 


\section{Background}

Gastrointestinal tumors are a common malignant tumor affecting individuals worldwide [1]. The high mortality rate associated with gastrointestinal tumors is a result of the tumor invading and metastasizing to other tissues. The increasing resistance observed in gastrointestinal tumors receiving chemotherapy and targeted therapy has led to an increased challenge when treating this disease [2-4]. There is extensive evidence that tumor-infiltrating lymphocytes, such as tumor - associated macrophages (TAMs), influence both the prognosis and efficacy of chemotherapy and immunotherapy $[5,6]$, as well as tumor angiogenesis, progression and metastasis [7]. Therefore, it is crucial to identify novel immune-related therapeutic targets and elucidate the potential mechanisms behind the immune interactions linked to gastrointestinal tumors.

Integrins are a large family of heterodimeric integral membrane proteins that function in cell surface adhesion and signaling pathways. Integrin Subunit Alpha 5 (ITGA5), primarily binds to Integrin Subunit Beta 1 (ITGB1) to form a $\alpha 5 \beta 1$ heterodimer $[8,9]$. Recently, it has become clear that ITGA5 is essential for cancer proliferation, migration, invasion and metastasis [10-13]. In addition, ITGA5 was shown to maintain cancer cell stemness and chemotherapy resistance $[14,15]$. Interestingly, ITGA5 was identified as a critical factor for promoting the differentiation of human mesenchymal stromal cells in vivo [16]. Recent studies revealed that ITGA5 plays a crucial role in different tumor cell subgroups and cell-cell interactions. Importantly, there is evidence revealing that immune components existing in the tumor microenvironment (TME) comprehensively regulate the biological behavior of the tumor through mutual interactions [17]. Furthermore, immunotherapy, especially the application of immune checkpoint modulators, is an efficient treatment strategy for solid tumors $[18,19]$.

However, the important role of ITGA5 in gastrointestinal tumors and its relationship with tumor immunity are still unclear. Here, we explored the expression level, prognostic value, protein interaction network and enrichment analysis of ITGA5 in gastrointestinal tumors. More importantly, the correlation between ITGA5 and tumor-infiltrating immune cells and markers in different tumor microenvironments was also analyzed. Our result supported the pro-oncogenic effect of ITGA5 and revealed the overexpression of ITGA5 may have a potential and important relationship with tumor-immune infiltration.

\section{Methods}

\section{Clinical tissue specimens}

The tissue samples used for immunohistochemistry (IHC) staining and western blot were collected from patients diagnosed with gastric cancer at the First Affiliated Hospital of Anhui Medical University. All patients have already provided written informed consent. This work was approved by the Academic Committee of The First Affiliated Hospital of Anhui Medical University (certification no. Quick-PJ 2020-11-14) and was conducted following the Declaration of Helsinki.

\section{Oncomine analysis}

Expression of ITGA5 mRNA levels were analyzed to compare normal and tumor tissues in various cancer types using the Oncomine database (https://www. oncomine.org) $[20,21]$. The filter condition was set to a $P$ value $<0.001$, fold change $>1.5$, gene rank: $10 \%$, data type: mRNA.

\section{PrognoScan analysis}

PrognoScan database (http://www.abren.net/ PrognoScan) was used to identify the correlation between ITGA5 expression and prognosis in various cancers across a large collection of publicly available microarray datasets [22]. The threshold was adjusted to a Cox $P$-value $<0.05$.

\section{Kaplan-Meier plotter analysis}

Kaplan-Meier plotter (https://kmplot.com) possesses gene expression data and survival information associated with 1065 gastric cancer patients [23]. To evaluate differential expression of ITGA5 mRNA levels and the effects on patient progression, Kaplan-Meier survival curves for overall survival (OS) and disease or progression free survival (DFS or PFS) were generated for patients containing low and high ITGA5 mRNA expression levels. In addition, we used the Kaplan-Meier Plotter to evaluate the relationship between the expression of ITGA5 and the clinicopathological characteristics of gastric cancer patients. Results contained a hazard ratio (HR) with a 95\% confidence interval (CI) and log rank $P$ value.

\section{TIMER analysis}

Tumor Immune Estimation Resource (TIMER) database (https://cistrome.shinyapps.io/timer) is a publicly available comprehensive resource for systematic analysis of tumor immune-infiltrates [24]. It includes 10,897 samples across 32 different cancer types from The Cancer Genome Atlas (TCGA). The correlation between ITGA5 expression levels and immune infiltrates including $B$ cells, CD4+ T cells, CD8+ T cells, neutrophils, macrophages and dendritic cells, were explored using the gene module in various cancer types. The correlation between genes markers of tumor-infiltrating immune cells and ITGA5 expression was analyzed using the correlation module. Gene markers included CD8+ T cells, general T 
cells, B cells, monocytes, TAMs, M1 macrophages, M2 macrophages, neutrophils, natural killer (NK) cells, dendritic cells (DCs), T-helper 1 (Th1) cells, T-helper 2 (Th2) cells, follicular helper $\mathrm{T}$ (Tfh) cells, T-helper 17 (Th17) cells, Tregs and exhausted T cells. ITGA5 expression was plotted on the $\mathrm{X}$-axis and the expression of related marker genes were represented as gene symbols on the Y-axis. Correlation coefficients were estimated using Spearman's correlation method. Gene expression levels were shown as $\log 2$ RSEM.

\section{GEPIA2 analysis}

Gene expression Profiling Interactive Analysis 2 (GEPI A2) (http://gepia2.cancer-pku.cn) is an updated and enhanced version of GEPIA that supports 198,619 isoforms and 84 cancer subtypes $[25,26]$. In our study, the "Expression DIY" and "Survival" module of GEPIA2 were used to determine the correlation between ITGA5 expression and prognosis in pancreatic and esophageal cancers.

\section{Immunohistochemistry staining analysis}

Collected tissue specimens were formalin fixed and embedded with paraffin. Tissue sections ( $4 \mu \mathrm{m}$ thickness) were used in IHC staining analyses as previously described [27]. The intensity of immunostaining and the percentage of positive cells were used to determine the immunoreactivity to proteins. The density grading of intensity was analyzed as follows: 0:no staining, 1:weak staining; 2: medium staining, and 3: strong staining. The proportion of positive cells was further classified as 0 : < $1 \% ; 1: 1-30 \%, 2: 30-70 \%$, and 3:> 70\%. Semi-quantitative assessment and final immunostaining scores were determined by multiplying the proportion score and intensity scores. Scores 0, 1, 2 and 3 indicated low expression levels, while scores 4, 6 and 9 indicated high expression levels. IHC results were evaluated by two pathologists using a blind test and differences were resolved through consensus. Antibody information is listed in Additional file: Table S1.

\section{Western blot analysis}

All the collected tissues were cut and ground into a homogenate. Using RIPA buffer (Radio-Immunoprecipitation assay buffer, Beyotime) to lyse aggregated proteins in the cells. In addition, the concentrations were detected with the help of the BCA Protein Assay Kit (Beyotime). Segregation of equivalent quantities of proteins was made using the SDS-PAGE, followed by transferring to PVDF membranes (Millipore, Boston, MA, USA). After that, the membrane was incubated with the targeted primary antibody overnight at $4{ }^{\circ} \mathrm{C}$. After washing, incubation of the membranes was performed with the corresponding secondary antibody for $2 \mathrm{~h}$ at the room temperature. GAPDH was used as an internal loading control. The findings were analyzed with the help of the ECL detection system (Pierce Biotech, Rockford, IL, USA). Antibody information is listed in Additional file: Table S2.

\section{GeneMANIA analysis}

GeneMANIA (http://genemania.org/) is used to construct a protein-protein interaction (PPI) network and analyze the function of interactive genes [28]. This online tool uses bioinformatic methods to display a list of interacting genes, including gene co-expression, physical interactions, gene co-localization, gene enrichment analysis and website prediction. GeneMANIA was used to construct the PPI network for ITGA5.

\section{Metascape analysis}

Metascape (https://metascape.org/gp/index.html) is a gene function annotation website with obvious advantages of wide coverage and fast updating [29]. It integrates multiple authoritative data resources such as Gene Ontology (GO), Kyoto Encyclopedia of Genes and Genomes (KEGG) pathway, UniProt and DrugBank to complete thorough pathway enrichment and biological process annotation. Genes interacting with ITGA5 were put into Metascape to perform GO and KEGG annotation.

\section{Statistical analysis}

All statistical analyses were performed using SPSS 21.0 software (IBM Corp; Armonk, NY). Survival curves and relative results generated from PrognoScan, KaplanMeier Plotter and GEPIA2 databases were shown with HR and $P$ or Cox $P$ values from a log-rank test. Correlation analyses in TIMER were evaluated using Spearman's correlation. Associations between ITGA5 expression and IHC results in patients were evaluated using Pearson's $\mathrm{x} 2$ test. Student's t-test was used to determine the significance for the western blot experiments. $P$-value of $<0.05$ was considered as statistically significant.

\section{Results}

\section{Pan-cancer analysis of ITGA5 expression levels}

To determine ITGA5 mRNA expression levels in both normal and tumor tissues, Oncomine was interrogated to analyze ITGA5 expression in various cancer types. The expression levels of ITAG5 were greater in colorectal, esophageal, gastric and pancreatic cancers relative to normal tissues (Fig. 1a). In addition, the transcriptional levels for ITGA5 were analyzed using RNA-seq data for multiple malignancies in the TCGA with the use of TIMER. Results revealed significant 


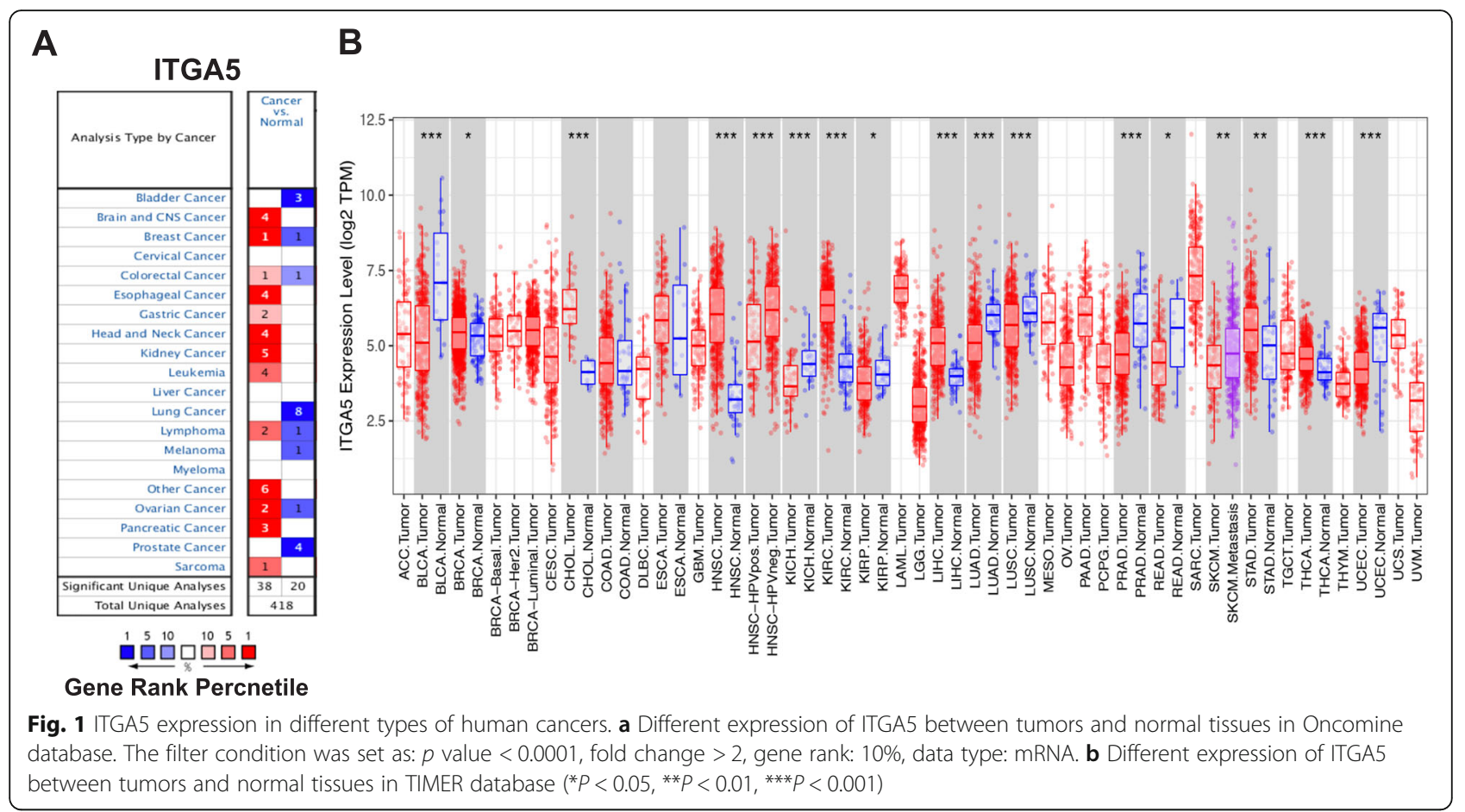

differences in ITGA5 expression levels when comparing normal and tumor tissues. Hepatocellular carcinoma (LIHC) and gastric adenocarcinoma (STAD) were significantly higher compared with normal tissue levels (Fig. 1b).

\section{Correlation between ITGA5 expression levels and patient prognosis}

To further identify the prognostic potential of ITGA5 in various cancers, clinical data from TCGA were used to explore the prognostic value of ITGA5 expression level using GEPIA2. High expression of ITGA5 was marginally correlated with poor prognosis in pancreatic cancer $(\mathrm{OS} H R=1.6, P=0.12$; DFS $\mathrm{HR}=$ 2.1, $P=0.015$ ) (Fig. 2a-b) and esophageal cancer (OS $\mathrm{HR}=1.4, P=0.37$; DFS HR =1.2, $P=0.52)$ (Fig. 2c-d). Subsequently, the Kaplan-Meier plotter database was used to determine the prognostic value of ITGA5. Significant differences were observed between ITGA5 expression and prognosis in gastric cancer (OS HR $=$ 2.4, $95 \% \mathrm{CI}=1.96$ to $2.97, P<1 \mathrm{e}-16$; DFS $\mathrm{HR}=2.69$, $95 \% \mathrm{CI}=2.04$ to $3.54, P=2.2 \mathrm{e}-13$ ) (Fig. $2 \mathrm{e}-\mathrm{f}$ ) and live cancer $(\mathrm{OS} \mathrm{HR}=1.73,95 \% \mathrm{CI}=1.22$ to $2.44, P=$ 0.0017; DFS HR $=1.23,95 \% \mathrm{CI}=0.88$ to $1.72, P=$ 0.23) patients (Fig. 2g-h). In addition, the PrognoScan database was used to investigates the relationship between ITGA5 mRNA levels and the survival of cancer patients using high-throughput analysis and detailed clinical prognosis data. ITGA5 expression was found to significantly impact prognosis in colorectal.
Specifically, the cohorts (GSE17536) [30] included 177 samples at different stages of colorectal cancer and showed a remarkable association between high ITGA5 expression levels and poor prognosis (OS HR $=1.66$, $95 \% \mathrm{CI}=1.16$ to 2.37 , Cox $P=0.005$; DFS HR $=2.97$, $95 \% \mathrm{CI}=1.70$ to 5.21 , Cox $P=0.0004$ ) (Figs. $2 \mathrm{i}-\mathrm{j}$ ) in colorectal cancer.

Interestingly, we also found that ITGA5 also has a significant impact on the prognosis of patients in some non-gastrointestinal tumors. High expression of ITGA5 was also associated with poor prognosis in lung cancer $(\mathrm{OS} H R=1.6,95 \% \mathrm{CI}=1.4$ to 1.81 , $P=5.9 \mathrm{e}-13$; DFS $\mathrm{HR}=1.75,95 \% \mathrm{CI}=1.44$ to 2.12 , $P=1.2 \mathrm{e}-08$ ) and breast cancer (OS $\mathrm{HR}=1.21,95 \%$ $\mathrm{CI}=0.96$ to $1.52, P=0.11$; DFS $\mathrm{HR}=1.28,95 \% \mathrm{CI}=$ 1.14 to $1.44, P=4.1 \mathrm{e}-05$ ) (Additional file: Fig. S1). Similarly, the cohorts (GSE26712) [31] showed that high ITGA5 expression levels were correlated with poor prognosis $(\mathrm{OS} \mathrm{HR}=1.58,95 \% \mathrm{CI}=1.06$ to 2.36, Cox $P=0.025$; DFS HR $=1.54,95 \% \mathrm{CI}=1.06$ to 2.24 , Cox $P=0.025$ ) in ovarian cancers (Additional file: Fig. S1).

\section{Relationship between ITGA5 expression and immune infiltration levels in gastrointestinal cancers}

Recent work has shown that gastrointestinal tumors exhibit extensive immune infiltration characteristics [3234]. Therefore, to better understand the role of ITGA5 in gastrointestinal tumors, the relationship between ITGA5 expression and immune infiltration in 


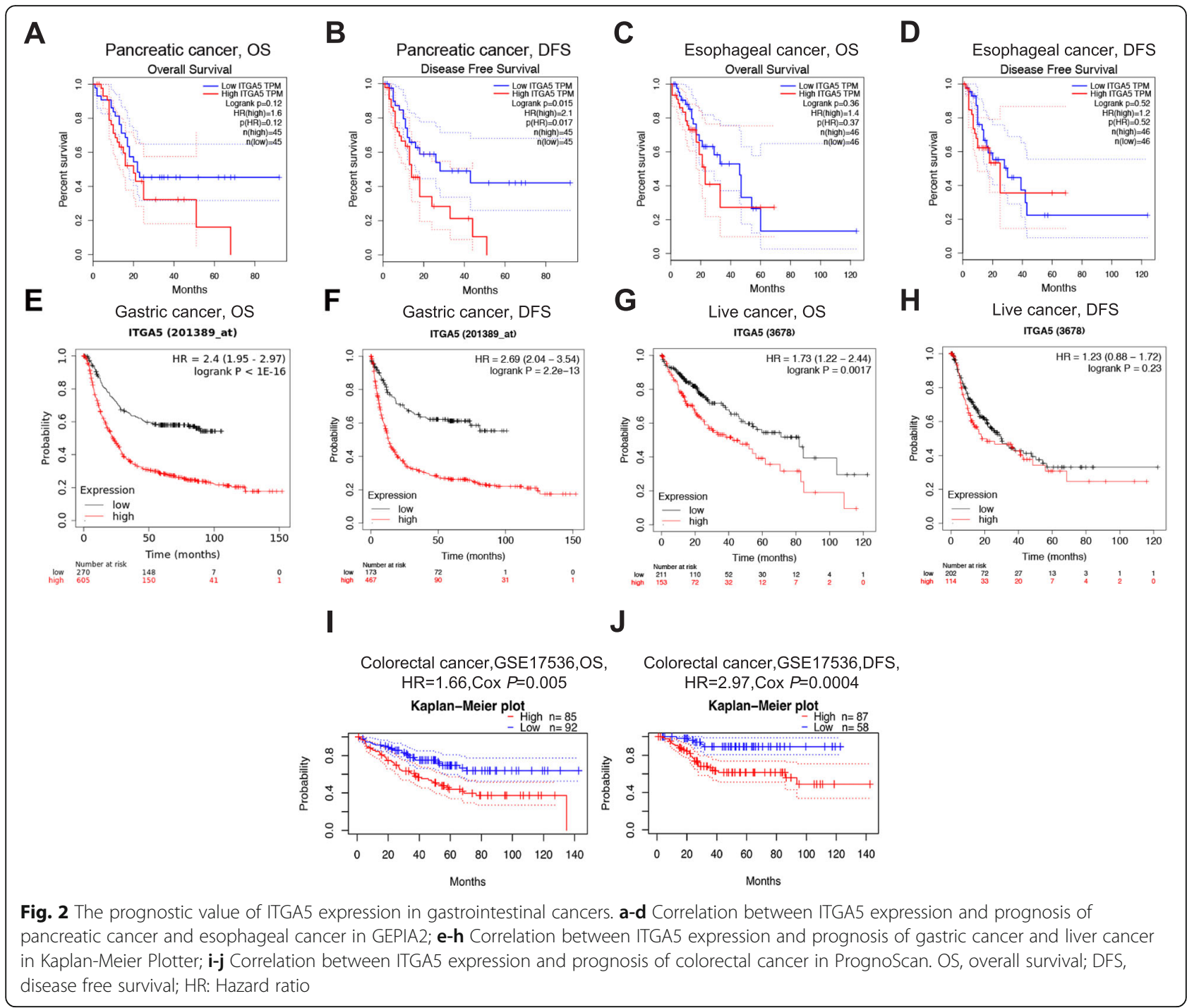

gastrointestinal tumors was investigated using the TIME $\mathrm{R}$ database. ITGA5 expression was found to be significantly correlated with tumor purity in colon adenocarcinoma (COAD), esophageal carcinoma (ESCA), STAD and rectum adenocarcinoma (READ) $(P<0.05), \mathrm{CD} 8+$ cell in COAD, LIHC and pancreatic adenocarcinoma (PAAD), CD4 + T cells in COAD, PAAD, LIHC, READ and STAD $(P<0.05)$ (Fig. 3a-f). Furthermore, ITGA5 expression was significantly associated with macrophages and dendritic cells in COAD, ESCA, READ, LIHC, PAAD and STAD $(P<0.05)$ (Fig. 3a-f). ITGA5 expression was also significantly associated with neutrophils in COAD, LIHC, READ, PAAD and STAD $(P<0.05)$ (Fig. 3a-f).

Specifically, ITGA5 expression levels showed significantly positive correlations with infiltrating levels of CD8 $+\mathrm{T}$ cells $(\mathrm{r}=0.248, P=4.18 \mathrm{e}-07), \mathrm{CD} 4+\mathrm{T}$ cells $(\mathrm{r}=0.423, P=6.67 \mathrm{e}-19)$, macrophages $(\mathrm{r}=0.545, P=$ 1.20e-32), neutrophils $(\mathrm{r}=0.590, \quad P=4.92 \mathrm{e}-39)$ and dendritic cells $(\mathrm{r}=0.556, P=5.48 \mathrm{e}-34)$ in COAD (Fig. 3a). Similarly, positive correlations were identified with infiltrating levels of CD4+ T cells $(r=0.426, P=$ 1.52e-17), macrophages $(\mathrm{r}=0.447, P=1.42 \mathrm{e}-19)$, neutrophils $(\mathrm{r}=0.189, P=2.47 \mathrm{e}-04)$ and dendritic cells $(\mathrm{r}=0.28, P=4.19 \mathrm{e}-08)$ in STAD (Fig. 3f). These results revealed that ITGA5 expression is closely associated with immune infiltration in gastrointestinal tumors.

\section{Correlation between ITGA5 expression levels and immune markers}

Gastric cancer and colorectal cancer are the most common gastrointestinal-related malignancies. Therefore, COAD and STAD were chosen to further investigate the relationship between ITGA 5 expression and immune marker genes of diverse immune cells 


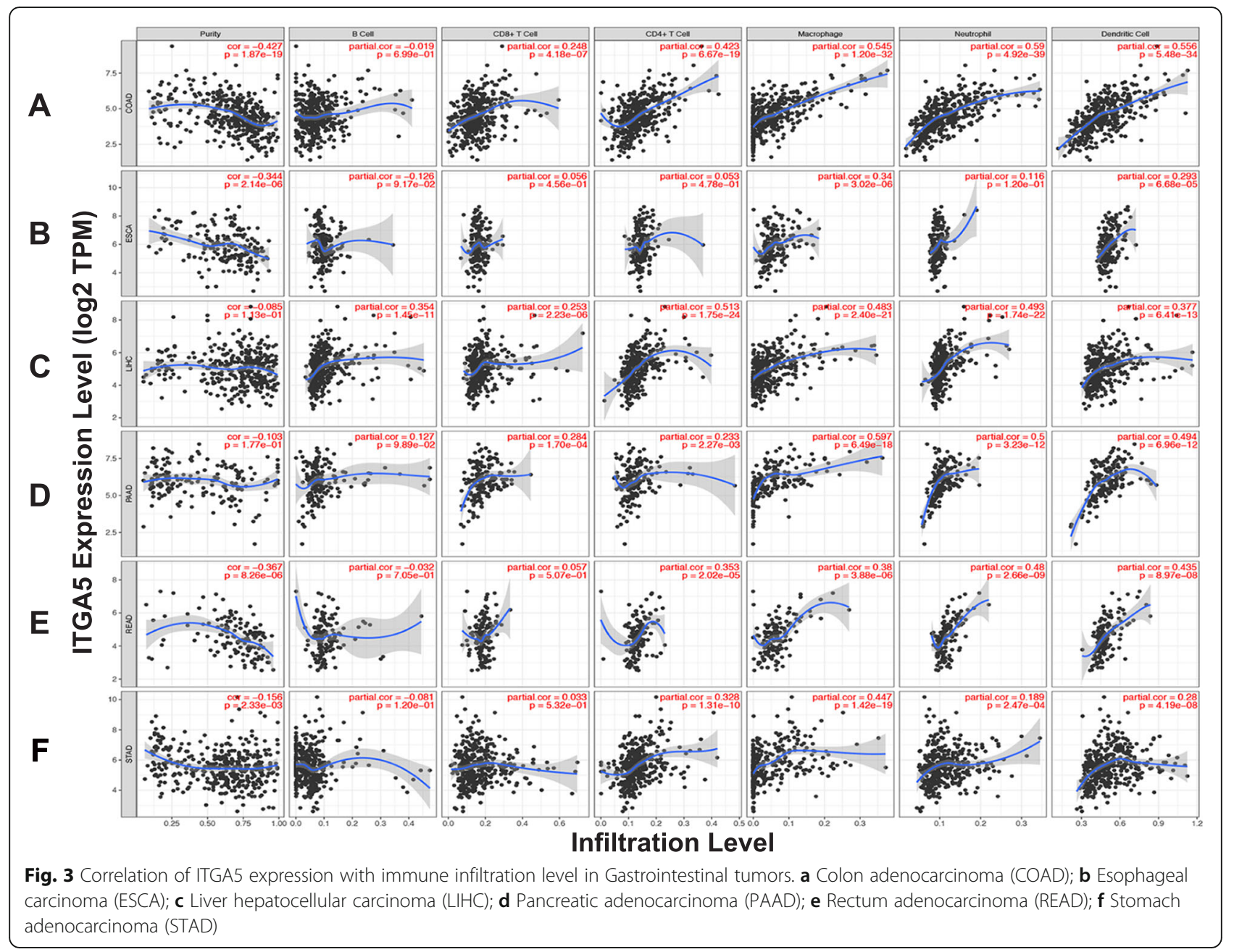

using TIMER databases. The immune cells analyzed included $\mathrm{CD} 8+\mathrm{T}$ cells, general $\mathrm{T}$ cells, different functional $\mathrm{T}$ cells, B cells, monocytes, TAMs, M1 macrophages and M2 macrophages, neutrophils, NK cells and dendritic cells. After adjusting correlation by purity, ITGA5 expression was found to be significantly correlated with immune markers of most immune cells in STAD and COAD (Table 1 and Fig. 4a-h). Immune markers for monocytes, TAMs, M2 and Th2 phenotypes were found to be significantly and positively correlated with ITGA5 expression levels in COAD and STAD $(P<0.05$; Figs. 4a-h).

High ITGA5 expression affects the prognosis of gastric cancer patients exhibiting lymph node metastasis

To better understand the relationship between ITGA5 expression levels and clinicopathological features, further research was focused on gastric cancer. According to Kaplan-Meier Plotter database analyses, overexpression of ITGA5 is strongly correlated with the deterioration of OS and PFS based on gender, differentiation and Lauren classification $(P<0.05)$ (Table 2$)$. In addition, stage I through IV cancer patients with high expression levels of ITGA5 showed worse OS $(P<0.05)$ (Table 2$)$. Similarly, high expression levels of ITGA5 were associated with worse PFS in stage II through IV gastric cancer patients $(P<0.05)$ but not in stage I gastric cancer patients (Table 2). However, there was no strong correlation observed between ITGA5 expression levels and patient prognosis in stage No (OS $\mathrm{HR}=1.92, P=0.13$; PFS $\mathrm{HR}=1.95, P=0.11$ ), mixed Lauren classification (OS $\mathrm{HR}=1.88, P=0.22$; PFS $\mathrm{HR}=0.48, P=0.16$ ) or poor differentiation (OS HR $=0.75, P=0.16$; $\mathrm{PFS} H R=$ 1.39, $P=0.25$ ) (Table 2). Moreover, high ITGA5 levels express the highest $\mathrm{HR}$ value of $\mathrm{N} 1$ with $\mathrm{OS}$ and PFS among four $\mathrm{N}$ categories (Table 2). These results indicate that the expression levels of ITGA5 are related to lymph node metastasis in gastric cancer patients. 
Table 1 Correlation analysis between ITGA5 and markers of immune cells in TIMER database

\begin{tabular}{|c|c|c|c|c|c|c|c|c|c|}
\hline \multirow[t]{3}{*}{ Description } & \multirow[t]{3}{*}{ Gene markers } & \multicolumn{4}{|l|}{ COAD } & \multicolumn{4}{|l|}{ STAD } \\
\hline & & \multicolumn{2}{|l|}{ None } & \multicolumn{2}{|l|}{ Purity } & \multicolumn{2}{|l|}{ None } & \multicolumn{2}{|l|}{ Purity } \\
\hline & & Cor & $P$ & Cor & $P$ & Cor & $P$ & Cor & $P$ \\
\hline \multirow[t]{2}{*}{ CD8+ T cell } & CD8A & 0.34 & $* * *$ & 0.235 & $* * *$ & 0.152 & $* *$ & 0.134 & $* *$ \\
\hline & CD8B & 0.22 & $* * *$ & 0.168 & $* * *$ & 0.094 & 0.055 & 0.094 & 0.066 \\
\hline \multirow[t]{3}{*}{ T cell (general) } & CD3D & 0.284 & $* * *$ & 0.127 & $*$ & 0.103 & * & 0.07 & 0.175 \\
\hline & CD3E & 0.381 & $* * *$ & 0.241 & $* * *$ & 0.381 & $* * *$ & 0.102 & 0.046 \\
\hline & CD2 & 0.348 & $* * *$ & 0.216 & $* * *$ & 0.348 & $* * *$ & 0.118 & 0.021 \\
\hline \multirow[t]{2}{*}{ B cell } & CD19 & 0.226 & $* * *$ & 0.072 & 0.150 & 0.226 & $* * *$ & 0.205 & $* * *$ \\
\hline & CD79A & 0.303 & $* * *$ & 0.147 & $* *$ & 0.303 & $* * *$ & 0.146 & $* *$ \\
\hline \multirow[t]{2}{*}{ Monocyte } & CD86 & 0.651 & $* * *$ & 0.583 & $* * *$ & 0.651 & $* * *$ & 0.313 & $* * *$ \\
\hline & CD115 (CSF1R) & 0.65 & $* * *$ & 0.584 & $* * *$ & 0.65 & $* * *$ & 0.423 & $* * *$ \\
\hline \multirow[t]{3}{*}{ TAM } & CCL2 & 0.607 & $* * *$ & 0.607 & $* * *$ & 0.659 & $* * *$ & 0.427 & $* * *$ \\
\hline & CD68 & 0.556 & $* * *$ & 0.497 & $* * *$ & 0.556 & $* * *$ & 0.21 & $* * *$ \\
\hline & IL10 & 0.461 & $* * *$ & 0.404 & $* * *$ & 0.392 & $* * *$ & 0.388 & $* * *$ \\
\hline \multirow[t]{3}{*}{ M1 Macrophage } & INOS (NOS2) & 0.064 & 0.172 & -0.125 & * & 0.035 & 0.475 & 0.042 & 0.411 \\
\hline & IRF5 & 0.296 & $* * *$ & 0.323 & $* * *$ & 0.193 & $* * *$ & 0.197 & $* * *$ \\
\hline & COX2(PTGS2) & 0.41 & $* * *$ & 0.359 & $* * *$ & 0.402 & $* * *$ & 0.398 & $* * *$ \\
\hline \multirow[t]{3}{*}{ M2 Macrophage } & CD163 & 0.700 & $* * *$ & 0.648 & $* * *$ & 0.444 & $* * *$ & 0.437 & $* * *$ \\
\hline & VSIG4 & 0.633 & $* * *$ & 0.567 & $* * *$ & 0.437 & $* * *$ & 0.444 & $* * *$ \\
\hline & MS4A4A & 0.597 & $* * *$ & 0.526 & $* * *$ & 0.378 & $* * *$ & 0.374 & $* * *$ \\
\hline \multirow[t]{3}{*}{ Neutrophils } & CD66b (CEACAM8) & -0.218 & $* * *$ & 0.207 & $* * *$ & 0.018 & 0.714 & 0.045 & 0.384 \\
\hline & CD11b (ITGAM) & 0.684 & $* * *$ & 0.624 & $* * *$ & 0.427 & $* * *$ & 0.418 & $* * *$ \\
\hline & CCR7 & 0.405 & $* * *$ & 0.274 & $* * *$ & 0.319 & $* * *$ & 0.292 & $* * *$ \\
\hline \multirow[t]{7}{*}{ Natural killer cell } & KIR2DL1 & 0.224 & $* * *$ & 0.173 & $* * *$ & 0.11 & * & 0.117 & $* * * *$ \\
\hline & KIR2DL3 & 0.168 & $* * *$ & 0.121 & 0.015 & 0.039 & 0.433 & 0.031 & 0.553 \\
\hline & KIR2DL4 & 0.222 & $* * *$ & 0.135 & $* *$ & -0.03 & 0.549 & -0.046 & 0.375 \\
\hline & KIR3DL1 & 0.267 & $* * *$ & 0.201 & $* * *$ & 0.092 & 0.062 & 0.076 & 0.138 \\
\hline & KIR3DL2 & 0.249 & $* * *$ & 0.177 & 0.177 & 0.08 & 0.102 & 0.074 & 0.149 \\
\hline & KIR3DL3 & 0.052 & 0.265 & 0.039 & 0.431 & -0.069 & 0.159 & -0.033 & 0.525 \\
\hline & KIR2DS4 & 0.194 & $* * *$ & 0.162 & $* *$ & 0.051 & 0.296 & 0.055 & 0.284 \\
\hline \multirow[t]{7}{*}{ Dendritic cell } & HLA-DPB1 & 0.501 & $* * *$ & 0.389 & $* * *$ & 0.136 & $* *$ & 0.101 & 0.051 \\
\hline & HLA-DQB1 & 0.297 & $* * *$ & 0.183 & $* * *$ & 0.068 & 0.169 & 0.04 & 0.441 \\
\hline & HLA-DRA & 0.46 & $* * *$ & 0.355 & $* * *$ & 0.076 & 0.120 & 0.044 & 0.394 \\
\hline & HLA-DPA1 & 0.486 & $* * *$ & 0.385 & $* * *$ & 0.09 & 0.069 & 0.056 & 0.281 \\
\hline & $\mathrm{BDCA}-1(\mathrm{CD} 1 \mathrm{C})$ & 0.304 & $* * *$ & 0.199 & $* * *$ & 0.246 & $* * *$ & 0.213 & $* * *$ \\
\hline & BDCA-4(NRP1) & 0.83 & $* * *$ & 0.794 & $* * *$ & 0.639 & $* * *$ & 0.63 & $* * *$ \\
\hline & CD11c (ITGAX) & 0.738 & $* * *$ & 0.675 & $* * *$ & 0.408 & $* * *$ & 0.392 & $* * *$ \\
\hline \multirow[t]{5}{*}{ Th1 } & T-bet (TBX21) & 0.43 & $* * *$ & 0.336 & $* * *$ & 0.183 & $* * *$ & 0.172 & $* * *$ \\
\hline & STAT4 & 0.343 & $* * *$ & 0.231 & $* * *$ & 0.222 & $* * *$ & 0.222 & $* * *$ \\
\hline & STAT1 & 0.451 & $* * *$ & 0.411 & $* * *$ & 0.076 & 0.124 & 0.071 & 0.169 \\
\hline & IFN- $\gamma($ IFNG) & 0.242 & $* * *$ & 0.183 & $* * *$ & -0.043 & 0.380 & -0.052 & 0.312 \\
\hline & TNF-a (TNF) & 0.383 & $* * *$ & 0.334 & $* * *$ & 0.236 & $* * *$ & 0.204 & $* * *$ \\
\hline \multirow[t]{2}{*}{ Th2 } & GATA3 & 0.442 & $* * *$ & 0.36 & $* * *$ & 0.22 & $* * *$ & 0.204 & $* * *$ \\
\hline & STAT6 & 0.132 & $* *$ & 0.121 & * & 0.199 & $* * *$ & 0.214 & $* * *$ \\
\hline
\end{tabular}


Table 1 Correlation analysis between ITGA5 and markers of immune cells in TIMER database (Continued)

\begin{tabular}{|c|c|c|c|c|c|c|c|c|c|}
\hline \multirow[t]{3}{*}{ Description } & \multirow[t]{3}{*}{ Gene markers } & \multicolumn{4}{|c|}{ COAD } & \multicolumn{4}{|l|}{ STAD } \\
\hline & & \multicolumn{2}{|l|}{ None } & \multicolumn{2}{|c|}{ Purity } & \multicolumn{2}{|l|}{ None } & \multicolumn{2}{|l|}{ Purity } \\
\hline & & Cor & $P$ & Cor & $P$ & Cor & $P$ & Cor & $P$ \\
\hline & STAT5A & 0.307 & $* * *$ & 0.275 & $* * *$ & 0.367 & $* * *$ & 0.368 & $* * *$ \\
\hline & IL13 & 0.3 & $* * *$ & 0.247 & $* * *$ & 0.167 & $* * *$ & 0.19 & $* * *$ \\
\hline \multirow[t]{2}{*}{ Tfh } & BCL6 & 0.643 & $* * *$ & 0.583 & $* * *$ & 0.503 & $* * *$ & 0.471 & $* * *$ \\
\hline & IL21 & 0.202 & $* * *$ & 0.154 & $* *$ & 0.029 & 0.563 & 0.012 & 0.809 \\
\hline \multirow[t]{2}{*}{ Th17 } & STAT3 & 0.417 & $* * *$ & 0.37 & $* * *$ & 0.462 & $* * *$ & 0.457 & $* * *$ \\
\hline & IL17A & 0.198 & $* * *$ & 0.224 & $* * *$ & -0.103 & * & -0.112 & * \\
\hline \multirow[t]{4}{*}{ Treg } & FOXP3 & 0.537 & $* * *$ & 0.454 & $* * *$ & -0132 & 0.244 & -0.107 & 0.395 \\
\hline & CCR8 & 0.543 & $* * *$ & 0.481 & $* * *$ & 0.123 & 0.280 & 0.055 & 0.642 \\
\hline & STAT5B & 0.356 & $* * *$ & 0.385 & $* * *$ & 0.381 & $* * *$ & 0.418 & $* * *$ \\
\hline & TGF $\beta$ (TGFB1) & 0.69 & $* * *$ & 0.606 & $* * *$ & 0.6 & $* * *$ & 0.591 & $* * *$ \\
\hline \multirow[t]{5}{*}{ T cell exhaustion } & PD-1 (PDCD1) & 0.395 & $* * *$ & 0.28 & $* * *$ & 0.175 & $* * *$ & 0.17 & $* * *$ \\
\hline & CTLA4 & 0.465 & $* * *$ & 0.28 & $* * *$ & 0.155 & $* *$ & 0.144 & $* *$ \\
\hline & LAG3 & 0.419 & $* * *$ & 0.317 & $* * *$ & 0.134 & $* *$ & 0.126 & $*$ \\
\hline & TIM-3 (HAVCR2) & 0.645 & $* * *$ & 0.584 & $* * *$ & 0.33 & $* * *$ & 0.33 & $* * *$ \\
\hline & GZMB & 0.099 & * & 0.077 & 0.122 & 0.068 & 0.169 & 0.05 & 0.332 \\
\hline
\end{tabular}

COAD Colon adenocarcinoma, STAD Stomach adenocarcinoma, None: age and tumor purity are not considered (it means that the tumor purity and age are not used to correct the results by using the partial Sperarman's correlation when performing this association analysis); Purity: tumor purity is considered (it means the tumor purity is used to correct the results when performing correlation analysis); Cor: Correlation coefficient; $P: P$ value; ${ }^{*} P<0.05,{ }^{* *} P<0.01,{ }^{* * *} P<0.001$

\section{ITGA5 protein expression and M2 and Th2 immune} marker genes in STAD

To confirm the results obtained from publicly available databases, IHC were performed on adjacent normal and STAD tumor tissues obtained from 40 gastric patients. Compared with adjacent normal tissues, ITGA5, CD163, STAT6 and GATA3 levels were greater in most tumor tissues (Fig. 5a). In addition, these results revealed that the expression levels of CD163 $\left(\chi^{2}=8.750, P=0.003\right)$, STAT6 $\left(\chi^{2}=8.174, P=\right.$ $0.004)$ and GATA3 $\left(X^{2}=5.079, P=0.024\right)$ in the ITGA5 high-expression group were significantly higher than what was observed in the ITGA5 lowexpression group (Table 3). Among the patients with higher ITGA5 expression levels, 12 patients showed higher CD163, STAT6 and GATA3 levels at the same time. In addition, we attempted to detect the proteins levels of ITGA5, CD163, STAT6 and GATA3 in patient tissues by western blot. As Fig. 5b, c shows, the expression levels in tumor tissues were indeed higher than that in adjacent normal tissues.

\section{ITGA5 PPI network and enrichment analyses}

PPI network analysis revealed interactions between ITGA5 and specific genes. As shown by GeneMANIA, genes interacting with ITGA5 included SPP1, ITGB1, ITGB3, COL18A1, HOXD3, ANGPTL3, CD9, FBN1, VEGFD, ITGA2B, ITGA4, FN1, FLT4, TLN1, ACVR
L1, FUBP1, THBS4, ACTN1, ANGPT2 and ITGA8 (Fig. 6a).

To further predict enriched function and pathway information of ITGA5 interacting genes, GO function and KEGG pathway analyses were performed using Metascape. According to GO term analysis, genes interacting with ITGA5 in the PPI network are mainly related with cell-substrate adhesion, regulation of leukocyte migration, response to wounding and myeloid cell differentiation. KEGG pathway analysis showed these genes are enriched in focal adhesion, PID avb3 integrin pathway and PID integrin5 pathway. Based on these results, ITGA5 and its interacting proteins were shown to play an important role in the integrin mediated signaling pathway, leukocyte migration, cell-substrate adhesion and other essential biological processes (Fig. 6b). In addition, Cytoscape was used to determine the relationship for the enriched terms and to build a network diagram (Fig. 6c and d).

\section{Discussion}

ITGA5 belongs to the integrin alpha chain family and interacts with ITGB1 to form a heterodimeric integral membrane protein - integrin $\alpha 5 \beta 1$ complex that performs diverse biological functions. Despite not knowing all of the functions performed by ITGA5, multiple studies have demonstrated that increased expression of ITGA5 is associated with poor prognosis in 


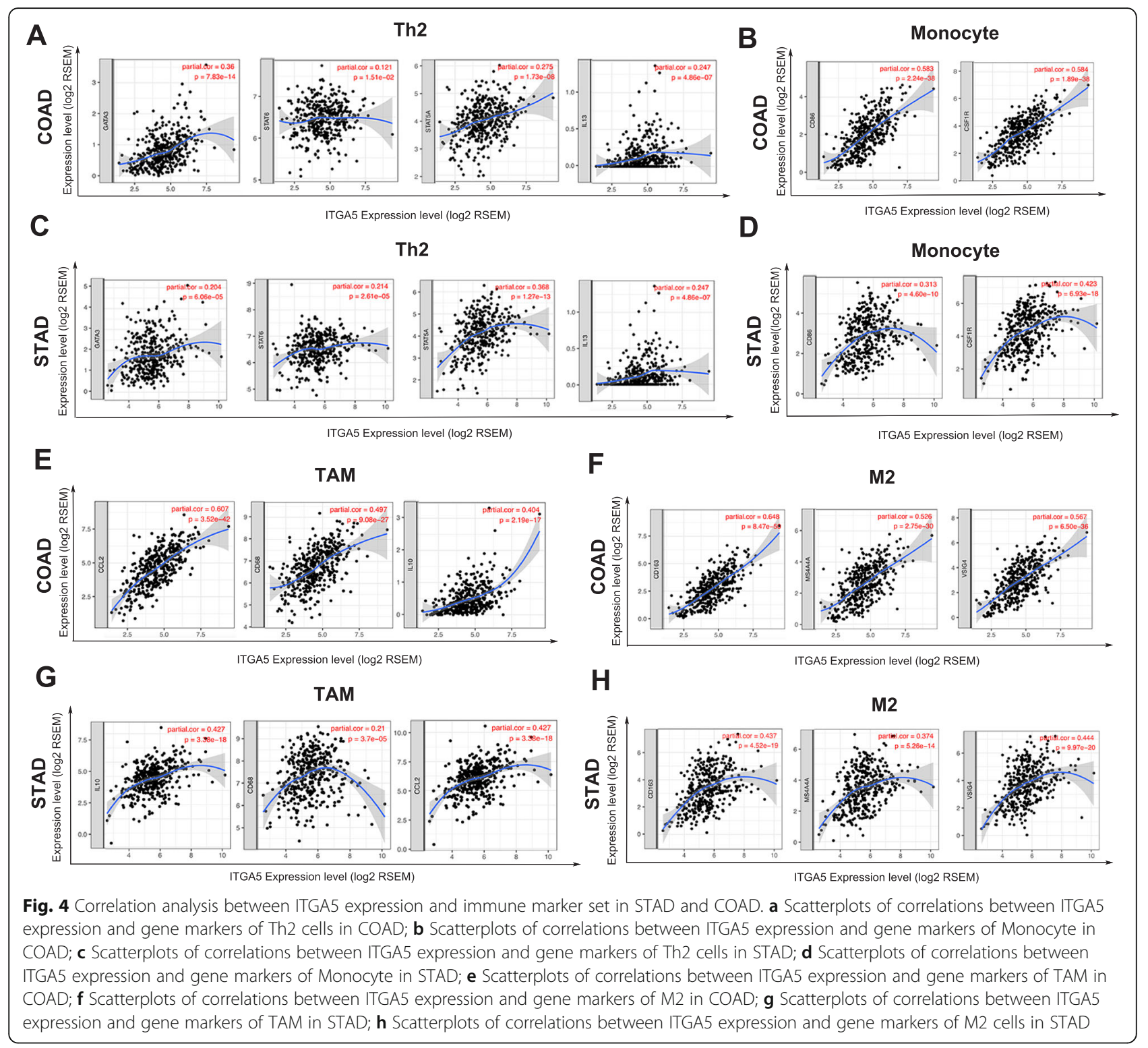

multiple tumors types, such as triple negative breast cancer [14], lung cancer [35], hepatocellular carcinoma [36] and ovarian cancer [37]. Here, public databases were used to determine ITGA5 expression levels in different cancer types. Compared to normal tissues, ITGA5 was generally overexpressed in different cancers including multiple types of gastrointestinal tumors. We explored whether the expression of ITGA5 was correlated with patient prognosis in these different tumors. Results revealed that high expression levels of ITGA5 were significantly correlated with worse OS and DFS in four types of gastrointestinal tumors, including colorectal, pancreatic, gastric and liver cancers. Although the results did not show statistical significance, esophageal cancer patients with high ITGA5 expression levels still showed a trend of high survival risk. To understand the clinical significance of ITGA5 in gastric cancer, the prognostic values for ITGA5 expression levels with various clinicopathological factors were determined. High expression of ITGA5 was correlated with poor prognosis in gastric cancer stages II-IV, T2-T4, N1-N3 and M0M1. These results demonstrated that ITGA5 has potential as a prognostic biomarker in gastrointestinal tumors.

Both innate and adaptive immune cells regulate the biological behavior of tumors and the response to treatment through direct contact or signal transduction mechanisms [17]. We therefore explored the relationship between ITGA5 expression levels and immune 
Table 2 Correlation of ITGA5 and clinicopathological factors in STAD from Kaplan-Meier Plotter database

\begin{tabular}{|c|c|c|c|c|c|c|}
\hline \multirow{2}{*}{$\begin{array}{l}\text { Clinicopathological } \\
\text { characteristics }\end{array}$} & \multicolumn{3}{|c|}{ Overall survival $(n=875)$} & \multicolumn{3}{|c|}{ Progression free survival $(n=640)$} \\
\hline & $\mathbf{N}$ & Hazard ratio & $P$-value & $\mathbf{N}$ & Hazard ratio & $P$-value \\
\hline \multicolumn{7}{|l|}{ Gender } \\
\hline Female & 236 & $2.74(1.68-4.46)$ & 2.6e-05 & 201 & $2.69(1.58-4.58)$ & 0.00014 \\
\hline Male & 544 & $2.75(2.12-3.57)$ & $2.2 \mathrm{e}-15$ & 437 & $2.55(2.00-3.25)$ & 4.2e-15 \\
\hline \multicolumn{7}{|l|}{ Stage } \\
\hline 1 & 67 & $3.62(1.00-13.12)$ & 0.036 & 60 & $2.42(0.63-9.31)$ & 0.19 \\
\hline 2 & 140 & $2.18(1.09-4.33)$ & 0.023 & 131 & $1.96(0.98-3.90)$ & 0.051 \\
\hline 3 & 305 & $2.31(1.61-3.30)$ & $2.4 \mathrm{e}-06$ & 186 & $1.87(1.29-2.72)$ & $8 e-04$ \\
\hline 4 & 148 & $1.78(1.2-2.64)$ & 0.0039 & 141 & $1.60(1.07-2.38)$ & 0.02 \\
\hline \multicolumn{7}{|l|}{ Stage $\mathbf{T}$} \\
\hline 2 & 241 & $2.00(1.29-3.11)$ & 0.0015 & 239 & $1.98(1.26-3.11)$ & 0.0024 \\
\hline 3 & 204 & $1.73(1.19-2.51)$ & 0.0036 & 204 & $1.37(0.98-1.91)$ & 0.065 \\
\hline 4 & 38 & $2.73(1.10-6.75)$ & 0.025 & 39 & $3.39(1.37-8.40)$ & 0.0054 \\
\hline \multicolumn{7}{|l|}{ Stage $\mathbf{N}$} \\
\hline 0 & 74 & $1.92(0.82-4.46)$ & 0.13 & 72 & $1.95(0.85-4.49)$ & 0.11 \\
\hline 1 & 225 & $3.13(1.99-4.94)$ & $2.3 e-07$ & 222 & $2.84(1.83-4.42)$ & $1.2 \mathrm{e}-06$ \\
\hline 2 & 121 & $2.56(1.62-4.05)$ & $3.1 \mathrm{e}-05$ & 125 & $2.08(1.33-3.25)$ & 0.00098 \\
\hline 3 & 76 & $2.1(1.22-3.61)$ & 0.0061 & 76 & $1.84(1.02-3.33)$ & 0.04 \\
\hline $1+2+3$ & 422 & $2.14(1.64-2.80)$ & $9.8 \mathrm{e}-09$ & 423 & $2.30(1.66-3.20)$ & $2.8 \mathrm{e}-07$ \\
\hline \multicolumn{7}{|l|}{ Stage M } \\
\hline 0 & 444 & $2.31(1.66-3.21)$ & $2.6 e-07$ & 443 & $2.12(1.55-2.91)$ & $1.6 \mathrm{e}-06$ \\
\hline 1 & 56 & $2.66(1.45-4.88)$ & 0.0011 & 56 & $1.69(0.92-3.12)$ & 0.088 \\
\hline \multicolumn{7}{|l|}{ Lauren classification } \\
\hline Intestinal & 320 & $2.84(2.07-3.90)$ & $1.6 \mathrm{e}-11$ & 263 & $2.70(1.74-4.20)$ & $4.2 \mathrm{e}-06$ \\
\hline Diffuse & 241 & $2.00(1.33-2.99)$ & 0.00061 & 231 & $2.10(1.33-3.32)$ & 0.0012 \\
\hline Mixed & 32 & $1.88(0.68-5.20)$ & 0.22 & 28 & $0.48(0.17-1.35)$ & 0.16 \\
\hline \multicolumn{7}{|l|}{ Differentiation } \\
\hline Poor & 165 & $0.75(0.50-1.12)$ & 0.16 & 121 & $1.39(0.79-2.45)$ & 0.25 \\
\hline Moderate & 67 & $2.16(1.08-4.30)$ & 0.025 & 67 & $2.23(1.15-4.32)$ & 0.015 \\
\hline
\end{tabular}

STAD Stomach adenocarcinoma, $N$ the number of patients

(Please put Table 2 at the end of the paragraph which begin with the subtitle "High ITGA5 expression affects the prognosis of gastric cancer patients exhibiting lymph node metastasis")

infiltration levels. Our results indicated that ITGA5 expression was significantly and negatively correlated with immune purity in four types of gastrointestinal tumors, including COAD, ECAD, STAD and READ. In STAD and $C O A D$, significant and positive relationships were observed between ITGA5 expression and infiltration levels for $\mathrm{CD} 4+\mathrm{T}$ cells, macrophages, neutrophils and dendritic cells. In addition, the relationship between ITGA5 expression levels and immune cell markers implicates underlying regulation in STAD and COAD. First, gene markers for Th2 cells (GATA3, STAT6, STAT5A and IL13) showed a positive correlation with ITGA5 expression. The M2 macrophage markers (CD163, VSIG4 and MS4A4A) showed a moderate or strong correlation. In addition, we also observed a significant correlation between ITGA expression and monocytes and TAMs in COAD and STAD. These results revealed a potential regulatory role for ITGA5 in the polarization of macrophages. TAMs, derived from mononuclear cells, are induced to differentiate into M2 cells by cytokines such as IL-4, IL-10 and IL-13, which are secreted by Th2 cells [38-40]. Moreover, M2 cells exhibit protumoral activity by promoting genetic instability, angiogenesis, stem cell nurturing and local immunosuppression [41, 42]. Subsequently, IHC and western blot were performed on adjacent normal and tumor tissues extracted from gastric cancer patients to find that Th2 cell markers such as STAT6, GATA3 and 


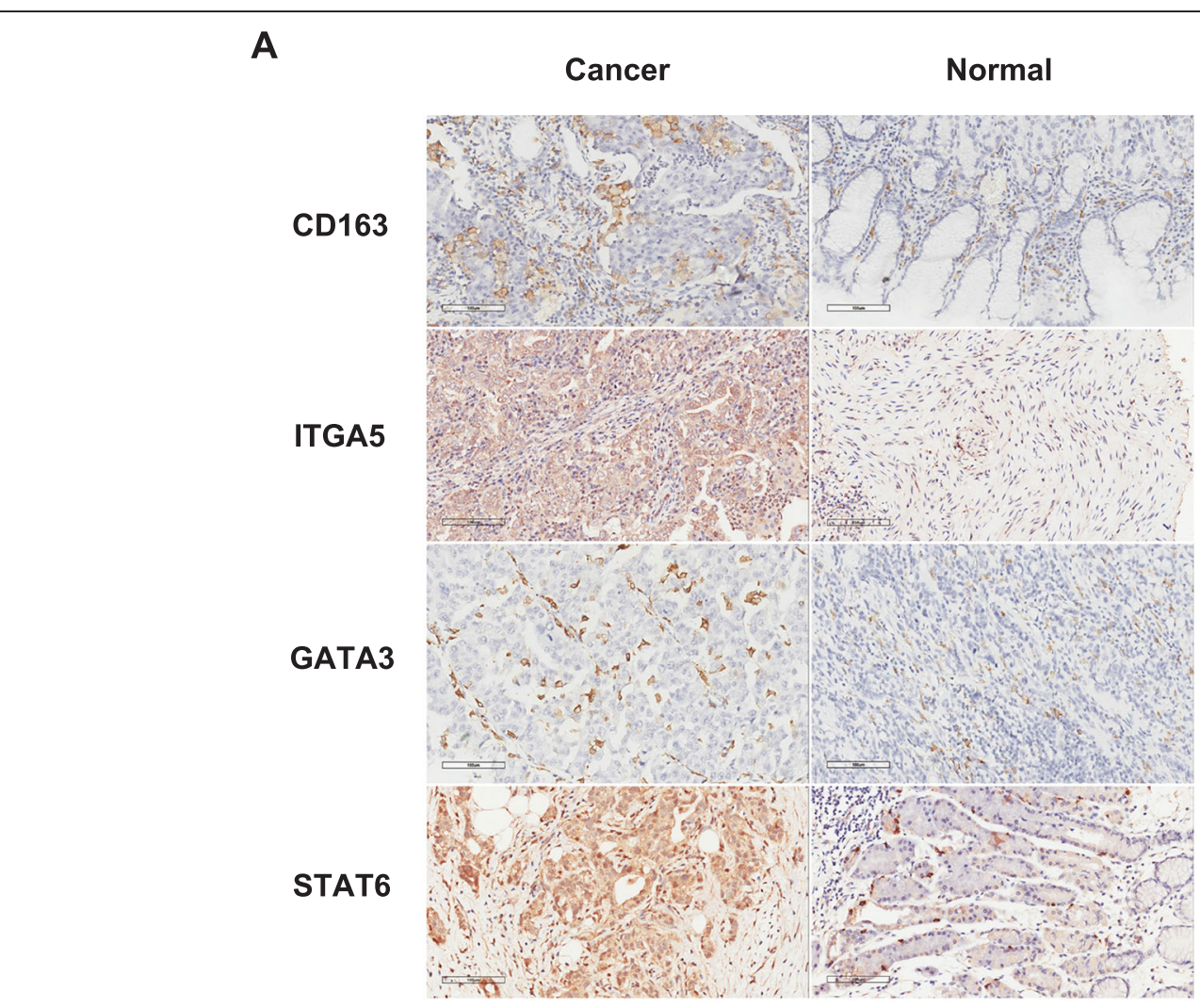

B

C
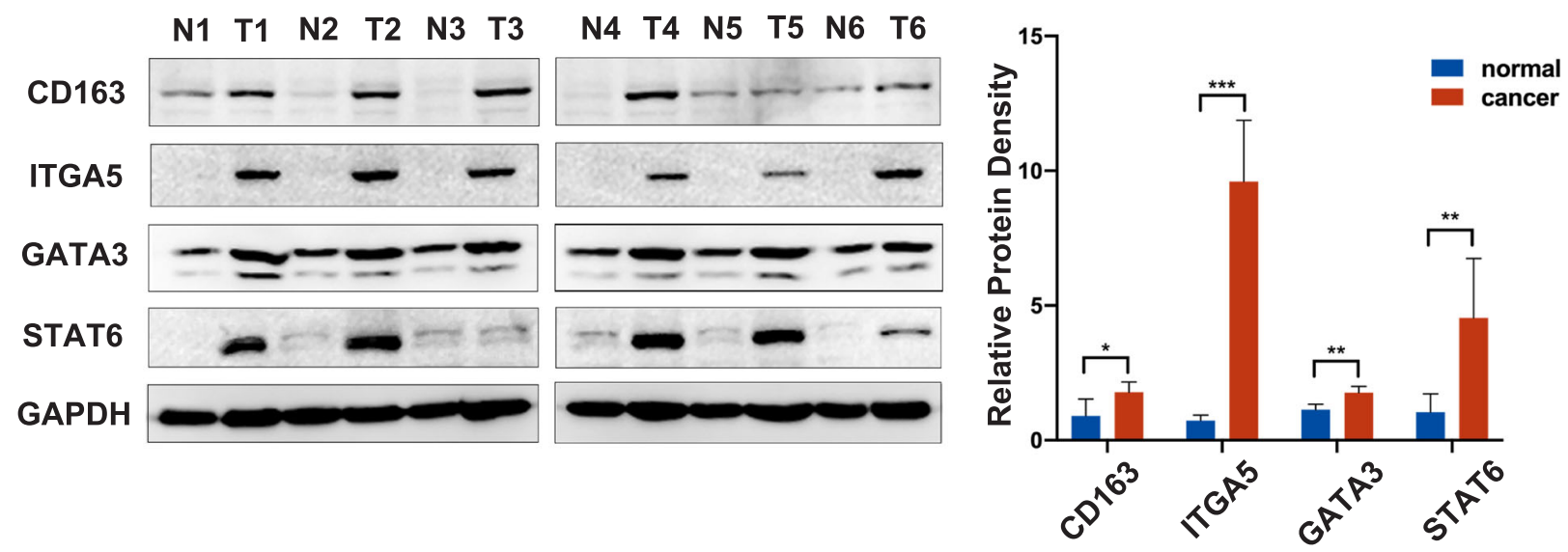

Fig. $5 \mathrm{IHC}$ and western blot analysis between ITGA5 and different markers of Th2 and M2 cells in gastric cancer tissues and adjacent normal tissues. a Representative IHC images of CD163, ITGA5, GATA3 and STAT6 in gastric cancer tissues and adjacent normal tissues; b Representative western blot images of CD163, ITGA5, GATA3 and STAT6 in 6 paired gastric cancer tissues (T) and adjacent normal tissues (N) (The full-length, original blots are presented in Additional file: Fig. S2); c Relative protein density of CD163, ITGA5, GATA3 and STAT6 in 6 paired gastric cancer tissues and adjacent normal tissues

the M2 cell polarization marker CD163 were significantly increased in patients with high ITGA5 expression levels. This suggested that ITGA5 may play an important role in promoting the recruitment and activation of monocytes, TAMs, Th2 cells and M2 cells in the tumor microenvironment.
Emerging evidence provides potential mechanisms to explain the correlation between ITGA5 expression levels and immune infiltration. Integrin $\alpha 5 \beta 1$ usually acts as a receptor for fibronectin to perform biological functions. Previous studies mainly focused on the role of ITGA5 in tumor cells, but recent studies found that ITGA5 is also 
Table 3 The protein expression level of ITGA5 and immune marker genes of M2 and Th2 cells in STAD

\begin{tabular}{|c|c|c|c|c|c|}
\hline & & ITGA5 high $(n=28)$ & ITGA5 low $(n=12)$ & $x^{2}$ & $P$-value \\
\hline \multirow[t]{2}{*}{ CD163 } & $\operatorname{High}(n=24)$ & 21 & 3 & 8.750 & 0.003 \\
\hline & Low $(n=16)$ & 7 & 9 & & \\
\hline \multirow[t]{2}{*}{ STAT6 } & $\operatorname{High}(n=29)$ & 24 & 5 & 8.174 & 0.004 \\
\hline & Low $(n=11)$ & 4 & 7 & & \\
\hline \multirow[t]{2}{*}{ GATA3 } & $\operatorname{High}(n=24)$ & 20 & 4 & 5.079 & 0.024 \\
\hline & $\operatorname{Low}(n=16)$ & 8 & 8 & & \\
\hline
\end{tabular}

(Please put Table 3 at the end of the paragraph which begin with the subtitle "ITGA5 protein expression and M2 and Th2 immune marker genes in STAD")

expressed in cancer-associated fibroblasts [43], TAMs [44] and chimeric antigen receptor expressing $\mathrm{T}$ cells [45]. Based on previous research, cancer-associated fibroblasts, which are regulators of immune cell recruitment and function, affect both innate and adaptive immune responses [46, 47]. Similarly, ITGA5 is expressed on the surface of TAMs and chimeric antigen receptor expressing $\mathrm{T}$ cells and can directly regulate the recruitment and alternative activation of immune cells. Interestingly, further work has shown that decreased expression of ITGA5 down-regulates pancreatic stellate cells differentiation into cancer-associated fibroblasts in pancreatic ductal cancer [15]. Importantly, pancreatic stellate cell are seen as the main source of cancerassociated fibroblasts [48]. The study presented here revealed an important role for ITGA5 in the differentiation and maturation of cells. These results partly explain the effects of ITGA5 expression on immune cell infiltration in malignant tumors and provides insight for further work. ITGA5 and its interacting proteins play an important role in integrin-mediated signaling pathways, leukocyte migration and cell-matrix adhesion as shown by the PPI network that was constructed as well as gene functional enrichment analysis. ITGA5 may act as an "anchor" for cell positioning, promoting the aggregation, adhesion and migration of partial immune cells and

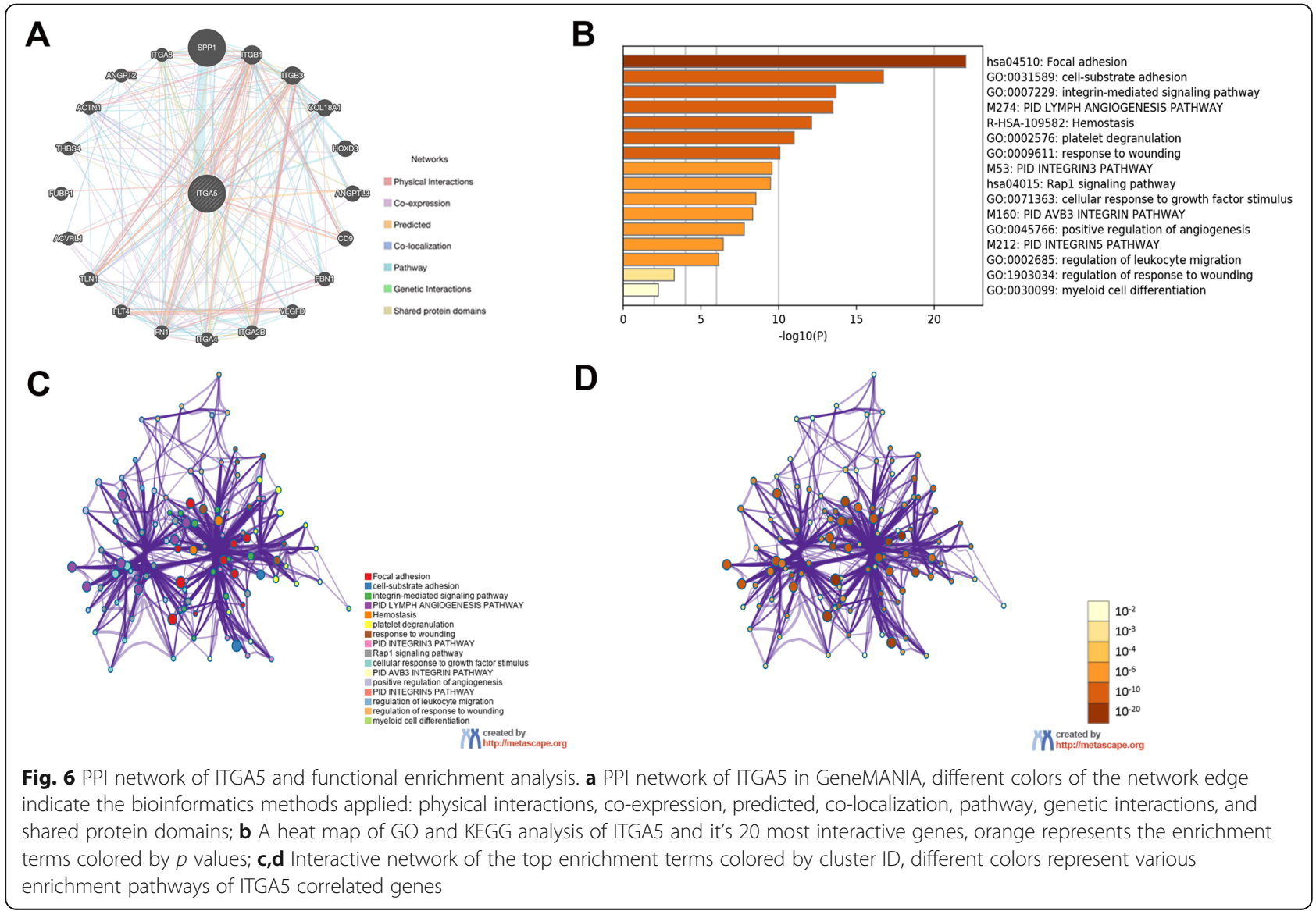


changing components of the tumor microenvironment. This may result in immune escape and suppression, ultimately accelerating tumor development and metastasis. In the future, the possible role and mechanisms behind ITAG5 in tumor immunity should be explored.

\section{Conclusions}

In summary, our study demonstrated that ITGA5 may be an essential regulator of tumor immune cell infiltration and a valuable prognostic biomarker in gastrointestinal tumors. Additional work is needed to fully elucidate the underlying mechanisms behind these observations.

\begin{abstract}
Abbreviations
ITGA5: Integrin subunit alpha 5; TAMs: Tumor - associated macrophages; ITGB1: Integrin subunit beta 1; TME: Tumor microenvironment; PPI: Proteinprotein interaction; GO: Gene ontology; KEGG: Kyoto encyclopedia of genes and genomes; OS: Overall survival; DFS: Disease free survival; PFS: Progression free survival; HR: Hazard ratio; Cl: Confidence interval; TCGA: The cancer genome atlas; NK: Natural killer; DCs: Dendritic cells; Th1: T-helper 1; Th2: Thelper 2; Tfh: Follicular helper T; Th17: T-helper 17; GEPIA2: Gene expression profiling interactive analysis 2; IHC: Immunohistochemistry; LIHC: Liver hepatocellular carcinoma; STAD: Stomach adenocarcinoma; COAD: Colon adenocarcinoma; ESCA: Esophageal carcinoma; READ: Rectum adenocarcinoma; PAAD: Pancreatic adenocarcinoma
\end{abstract}

\section{Supplementary Information}

The online version contains supplementary material available at https://doi. org/10.1186/s12885-021-07996-1.

Additional file 1 : Table S1. The information of antibody for immunohistochemistry. Table S2. The information of antibody for western blot.

Additional file $\mathbf{2}$ : Figure S1. The prognostic value of ITGA5 expression in non-gastrointestinal cancers. (A-D) Correlation between ITGA5 expression and prognosis of lung cancer and breast cancer in Kaplan-Meier Plotter; (E-F) Correlation between ITGA5 expression and prognosis of ovarian cancer in PrognoScan. OS, overall survival; DFS, disease free survival. Figure S2. The full-length, original blots for CD163 (A), ITGA5 (B), GATA3 (C) and STAT6 (D) in 6 paired gastric cancer tissues (T) and adjacent normal tissues $(\mathrm{N})$. (the order of samples from left to right are: marker, N1, T1, N2, T2, N3, T3, marker, N4, T4, N5, T5, N6, T6, marker).

\section{Acknowledgements}

Not applicable.

\section{Authors' contributions}

H.Z and G.W conceived and designed the experiments. H.Z, G.W and A.M.X extracted the data and performed the analysis, H.Z and G.W performed the experiments, H.Z, H.X.Z and A.M.X wrote the manuscript. H.Z and A.M.X revised the manuscript. All authors read and approved the final manuscript.

\section{Funding}

This study was supported by the National Natural Science Foundation of China (No. 81572350 to A. M. X), and the funder contributed to the collection and analysis of data, carrying out the experiment, writing the manuscript. In addition, this study was also supported by the project funding for the Construction of National and Provincial Key Clinical Specialty (No. Z155080000004 to the Department of General Surgery, The Fourth Affiliated Hospital of Anhui Medical University), this funder bodies (A. M. X. and G.W) played a key role in study design, experimental operation, data analysis and drafting and revising the manuscript.

\section{Availability of data and materials}

The datasets used and/or analyzed during the current study are available from the corresponding author on reasonable request.

\section{Declarations}

Ethics approval and consent to participate

This work was approved by the Academic Committee of The First Affiliated Hospital of Anhui Medical University and was conducted following the Declaration of Helsinki (certification no. Quick-PJ 2020-11-14). All patients provided written informed consent.

\section{Consent for publication}

Not applicable.

\section{Competing interests}

The authors declared no conflicts of interest in this work.

\section{Author details}

${ }^{1}$ Department of General Surgery, The First Affiliated Hospital of Anhui Medical University, Hefei 230001, People's Republic of China. ${ }^{2}$ Department of General Surgery, The Fourth Affiliated Hospital of Anhui Medical University, Hefei 230001, People's Republic of China. ${ }^{3}$ Department of Gastrointestinal Surgery, The First Affiliated Hospital of USTC, Division of Life Sciences and Medicine, University of Science and Technology of China, Hefei 230031, People's Republic of China.

Received: 13 August 2020 Accepted: 28 February 2021

Published online: 12 March 2021

\section{References}

1. Bray F, Ferlay J, Soerjomataram I, Siegel RL, Torre LA, Jemal A. Global cancer statistics 2018: GLOBOCAN estimates of incidence and mortality worldwide for 36 cancers in 185 countries. CA Cancer J Clin. 2018;68(6):394-424.

2. Van Cutsem E, Sagaert X, Topal B, Haustermans K, Prenen H. Gastric cancer. Lancet (London, England). 2016;388(10060):2654-64.

3. Becht E, de Reyniès A, Giraldo NA, Pilati C, Buttard B, Lacroix L, et al. Immune and stromal classification of colorectal Cancer is associated with molecular subtypes and relevant for precision immunotherapy. Clin Cancer Res. 2016;22(16):4057-66.

4. Myint ZW, Goel G. Role of modern immunotherapy in gastrointestinal malignancies: a review of current clinical progress. J Hematol Oncol. 2017; 10(1):86.

5. Waniczek D, Lorenc Z, Śnietura M, Wesecki M, Kopec A, Muc-Wierzgoń M. Tumor-associated macrophages and regulatory $T$ cells infiltration and the clinical outcome in colorectal Cancer. Arch Immunol Ther Exp. 2017;65(5): 445-54.

6. Zhang H, Liu H, Shen Z, Lin C, Wang X, Qin J, et al. Tumor-infiltrating neutrophils is prognostic and predictive for postoperative adjuvant chemotherapy benefit in patients with gastric Cancer. Ann Surg. 2018; 267(2):311-8.

7. Spranger S, Bao R, Gajewski TF. Melanoma-intrinsic $\beta$-catenin signalling prevents anti-tumour immunity. Nature. 2015;523(7559):231-5.

8. Morgan MR, Byron A, Humphries MJ, Bass MD. Giving off mixed signals-distinct functions of alpha5beta1 and alphavbeta3 integrins in regulating cell behaviour. IUBMB Life. 2009;61(7):731-8.

9. Marelli UK, Rechenmacher F, Sobahi TR, Mas-Moruno C, Kessler H. Tumor targeting via integrin ligands. Front Oncol. 2013;3:222.

10. Tani N, Higashiyama S, Kawaguchi N, Madarame J, Ota I, Ito Y, et al. Expression level of integrin alpha 5 on tumour cells affects the rate of metastasis to the kidney. Br J Cancer. 2003;88(2):327-33.

11. Sawada K, Mitra AK, Radjabi AR, Bhaskar V, Kistner EO, Tretiakova M, et al. Loss of E-cadherin promotes ovarian cancer metastasis via alpha 5-integrin, which is a therapeutic target. Cancer Res. 2008;68(7):2329-39.

12. Qian F, Zhang ZC, Wu XF, Li YP, Xu Q. Interaction between integrin alpha (5) and fibronectin is required for metastasis of B16F10 melanoma cells. Biochem Biophys Res Commun. 2005;333(4):1269-75.

13. Deng Y, Wan Q, Yan W. Integrin a5/ITGA5 promotes the proliferation, migration, invasion and progression of Oral squamous carcinoma by epithelial-Mesenchymal transition. Cancer Manag Res. 2019;11:9609-20. 
14. Xiao Y, Li Y, Tao H, Humphries B, Li A, Jiang Y, et al. Integrin a5 downregulation by miR-205 suppresses triple negative breast cancer stemness and metastasis by inhibiting the Src/Nav2/Rac1 pathway. Cancer Lett. 2018; 433:199-209.

15. Kuninty PR, Bansal R, De Geus SWL, Mardhian DF, Schnittert J, van Baarlen J, et al. ITGA5 inhibition in pancreatic stellate cells attenuates desmoplasia and potentiates efficacy of chemotherapy in pancreatic cancer. Sci Advances. 2019;5(9):eaax2770.

16. Hamidouche $Z$, Fromigué $O$, Ringe $J$, Häupl $T$, Vaudin $P$, Pagès JC, et al. Priming integrin alpha5 promotes human mesenchymal stromal cell osteoblast differentiation and osteogenesis. Proc Natl Acad Sci U S A. 2009; 106(44):18587-91.

17. Wu T, Dai Y. Tumor microenvironment and therapeutic response. Cancer Lett. 2017;387:61-8.

18. Valsecchi ME. Combined Nivolumab and Ipilimumab or Monotherapy in untreated melanoma. N Engl J Med. 2015;373(13):1270.

19. Borghaei $H$, Paz-Ares $L$, Horn L, Spigel DR, Steins M, Ready NE, et al. Nivolumab versus Docetaxel in advanced nonsquamous non-small-cell lung Cancer. N Engl J Med. 2015;373(17):1627-39.

20. Rhodes DR, Kalyana-Sundaram S, Mahavisno V, Varambally R, Yu J, Briggs BB, et al. Oncomine 3.0: genes, pathways, and networks in a collection of 18,000 cancer gene expression profiles. Neoplasia (New York, NY). 2007;9(2):166-80.

21. Rhodes DR, Yu J, Shanker K, Deshpande N, Varambally R, Ghosh D, et al. ONCOMINE: a cancer microarray database and integrated data-mining platform. Neoplasia (New York, NY). 2004;6(1):1-6.

22. Mizuno H, Kitada K, Nakai K, Sarai A. PrognoScan: a new database for metaanalysis of the prognostic value of genes. BMC Med Genet. 2009;2:18.

23. Lánczky A, Nagy Á, Bottai G, Munkácsy G, Szabó A, Santarpia L, et al. miRpower: a web-tool to validate survival-associated miRNAs utilizing expression data from 2178 breast cancer patients. Breast Cancer Res Treat. 2016;160(3):439-46.

24. Li T, Fan J, Wang B, Traugh N, Chen Q, Liu JS, et al. TIMER: a web server for comprehensive analysis of tumor-infiltrating immune cells. Cancer Res. 2017; 77(21):e108-e10.

25. Tang Z, Li C, Kang B, Gao G, Li C, Zhang Z. GEPIA: a web server for cancer and normal gene expression profiling and interactive analyses. Nucleic Acids Res. 2017;45(W1):W98-w102.

26. Tang Z, Kang B, Li C, Chen T, Zhang Z. GEPIA2: an enhanced web server for large-scale expression profiling and interactive analysis. Nucleic Acids Res. 2019;47(W1):W556-w60.

27. Wang G, Zhong WC, Bi YH, Tao SY, Zhu H, Zhu HX, et al. The prognosis of Peroxiredoxin family in breast Cancer. Cancer Manag Res. 2019;11:9685-99.

28. Warde-Farley D, Donaldson SL, Comes O, Zuberi K, Badrawi R, Chao P, et al. The GeneMANIA prediction server: biological network integration for gene prioritization and predicting gene function. Nucleic Acids Res. 2010;38(Web Server issue):W214-20.

29. Zhou Y, Zhou B, Pache L, Chang M, Khodabakhshi AH, Tanaseichuk O, et al. Metascape provides a biologist-oriented resource for the analysis of systems-level datasets. Nat Commun. 2019;10(1):1523.

30. Smith JJ, Deane NG, Wu F, Merchant NB, Zhang B, Jiang A, et al. Experimentally derived metastasis gene expression profile predicts recurrence and death in patients with colon cancer. Gastroenterology. 2010; 138(3):958-68.

31. Bonome T, Levine DA, Shih J, Randonovich M, Pise-Masison CA, Bogomolniy $F$, et al. A gene signature predicting for survival in suboptimally debulked patients with ovarian cancer. Cancer Res. 2008;68(13):5478-86.

32. Bijlsma MF, Sadanandam A, Tan P, Vermeulen L. Molecular subtypes in cancers of the gastrointestinal tract. Nat Rev Gastroenterol Hepatol. 2017; 14(6):333-42.

33. Leone RD, Powell JD. Metabolism of immune cells in cancer. Nat Rev Cancer. 2020;20(9):516-31.

34. Solinas C, Pusole G, Demurtas L, Puzzoni M, Mascia R, Morgan G, et al. Tumor infiltrating lymphocytes in gastrointestinal tumors: controversies and future clinical implications. Crit Rev Oncol Hematol. 2017;110:106-16.

35. Zheng W, Jiang C, Li R. Integrin and gene network analysis reveals that ITGA5 and ITGB1 are prognostic in non-small-cell lung cancer. OncoTargets Therap. 2016:9:2317-27.

36. Zhao X, Wu Y, Lv Z. miR-128 modulates hepatocellular carcinoma by inhibition of ITGA2 and ITGA5 expression. Am J Transl Res. 2015;7(9):1564-73.
37. Gong C, Yang Z, Wu F, Han L, Liu Y, Gong W. miR-17 inhibits ovarian cancer cell peritoneal metastasis by targeting ITGA5 and ITGB1. Oncol Rep. 2016; 36(4):2177-83.

38. Chen D, Xie J, Fiskesund R, Dong W, Liang X, LV J, et al. Chloroquine modulates antitumor immune response by resetting tumor-associated macrophages toward M1 phenotype. Nat Commun. 2018;9(1):873.

39. Xiang W, Shi R, Kang X, Zhang X, Chen P, Zhang L, et al. Monoacylglycerol lipase regulates cannabinoid receptor 2-dependent macrophage activation and cancer progression. Nat Commun. 2018;9(1):2574.

40. Chen Y, Song Y, Du W, Gong L, Chang H, Zou Z. Tumor-associated macrophages: an accomplice in solid tumor progression. J Biomed Sci. 2019;26(1):78.

41. Genard G, Wera AC, Huart C, Le Calve B, Penninckx S, Fattaccioli A, et al. Proton irradiation orchestrates macrophage reprogramming through NFKB signaling. Cell Death Dis. 2018;9(7):728.

42. Najafi M, Hashemi Goradel N, Farhood B, Salehi E, Nashtaei MS, Khanlarkhani $\mathrm{N}$, et al. Macrophage polarity in cancer: a review. J Cell Biochem. 2019; 120(3):2756-65

43. Lu L, Xie R, Wei $R$, Cai C, Bi D, Yin D, et al. Integrin a5 subunit is required for the tumor supportive role of fibroblasts in colorectal adenocarcinoma and serves as a potential stroma prognostic marker. Mol Oncol. 2019;13(12): 2697-714.

44. Xu M, Zhang S, Jia L, Wang S, Liu J, Ma X, et al. E-M, an engineered Endostatin with high ATPase activity, Inhibits the Recruitment and Alternative Activation of Macrophages in Non-small Cell Lung Cancer. Front Pharmacol. 2017:8:532.

45. Guha P, Cunetta M, Somasundar P, Espat NJ, Junghans RP, Katz SC. Frontline science: functionally impaired geriatric CAR-T cells rescued by increased a5 $\beta 1$ integrin expression. J Leukoc Biol. 2017;102(2):201-8.

46. Harper J, Sainson RC. Regulation of the anti-tumour immune response by cancer-associated fibroblasts. Semin Cancer Biol. 2014;25:69-77.

47. Jiang $H$, Hegde S, DeNardo DG. Tumor-associated fibrosis as a regulator of tumor immunity and response to immunotherapy. Cancer Immunol Immunotherap. 2017;66(8):1037-48

48. Schnittert J, Bansal R, Prakash J. Targeting pancreatic stellate cells in Cancer. Trends Cancer. 2019;5(2):128-42.

\section{Publisher's Note}

Springer Nature remains neutral with regard to jurisdictional claims in published maps and institutional affiliations.
Ready to submit your research? Choose BMC and benefit from:

- fast, convenient online submission

- thorough peer review by experienced researchers in your field

- rapid publication on acceptance

- support for research data, including large and complex data types

- gold Open Access which fosters wider collaboration and increased citations

- maximum visibility for your research: over 100M website views per year

At BMC, research is always in progress.

Learn more biomedcentral.com/submissions 